\title{
Comparison of Common Methodologies for the Determination of Knee Flexor Muscle Strength
}

Dan I Ogborn, PT, MSc(PT), PhD, CSCS $^{1}{ }^{\text {a }}$, Alix Bellemare, MSc ${ }^{2}$, Brittany Bruinooge, B Kin (AT), CAT(C) ${ }^{1}$, Holly Brown, B $\mathrm{Kin}^{3}$, Sheila McRae, PhD', Jeff Leiter, PhD ${ }^{2}$

1 Department of Physical Therapy, University of Manitoba; Pan Am Clinic Foundation, 2 Pan Am Clinic Foundation; Faculty of Kinesiology and Recreation Management, University of Manitoba, ${ }^{3}$ Pan Am Clinic Foundation

Keywords: dynamometry, hamstrings, knee flexion, muscle strength, nordic hamstring curl, strength assessment

https://doi.org/10.26603/001c.21311

\section{International Journal of Sports Physical Therapy}

Vol. 16, Issue 2, 2021

\begin{abstract}
Background
Knee flexion strength may hold important clinical implications for the determination of injury risk and readiness to return to sport following injury and orthopedic surgery. A wide array of testing methodologies and positioning options are available that require validation prior to clinical integration. The purpose of this study was to 1 ) investigate the validity and test-retest reliability of isometric knee flexion strength measured by a fixed handheld dynamometer (HHD) apparatus compared to a Biodex Dynamometer (BD), 2) determine the impact of body position (seated versus supine) and foot position (plantarvs dorsiflexed) on knee flexion peak torque and 3) establish the validity and test-retest reliability of the NordBord Hamstring Dynamometer.
\end{abstract}

\section{Study Design}

Validity and reliability study, test-retest design.

\section{Methods}

Forty-four healthy participants (aged $27 \pm 4.8$ years) were assessed by two raters over two testing sessions separated by three to seven days. Maximal isometric knee flexion in the seated and supine position at $90^{\circ}$ knee flexion was measured with both a BD and an externally fixed HHD with the foot held in maximal dorsiflexion or in plantar flexion. The validity and test-retest reliability of eccentric knee flexor strength on the NordBord hamstring dynamometer was assessed and compared with isometric strength on the BD.

\section{Results}

Level of agreement between HHD and BD torque demonstrated low bias (bias $-0.33 \mathrm{Nm}$, SD of bias $13.5 \mathrm{Nm}$; 95\% LOA $26.13 \mathrm{Nm},-26.79 \mathrm{Nm}$ ). Interrater reliability of the HHD was high, varying slightly with body position (ICC range $0.9-0.97, \mathrm{n}=44$ ). Isometric knee flexion torque was higher in the seated versus supine position and with the foot dorsiflexed versus plantarflexed. Eccentric knee flexion torque had a high degree of correlation with isometric knee flexion torque as measured via the $\mathrm{BD}(\mathrm{r}=0.61-0.86)$. The NordBord had high test-retest reliability $(0.993$ (95\%CI 0.983-0.997, $\mathrm{n}=19)$ for eccentric knee flexor strength, with an $\mathrm{MDC}_{95}$ of $26.88 \mathrm{~N}$ and $28.76 \mathrm{~N}$ for the left and right limbs respectively.

\footnotetext{
Corresponding Author: 


\section{Conclusion}

Common measures of maximal isometric knee flexion display high levels of correlation and test-retest reliability. However, values obtained by an externally fixed HHD are not interchangeable with values obtained via the BD. Foot and body position should be considered and controlled during testing.

\section{Level of Evidence}

$2 b$

\section{INTRODUCTION}

Impairment of muscular strength is linked to functional disability, ${ }^{1}$ and measurement in a clinical setting may be useful to identify those at increased risk of injury or readiness to return to sport or work following injury. Clinically, muscular strength can be assessed with different methodologies with manual muscle testing (MMT), hand-held dynamometry (HHD) and isokinetic dynamometry representing more common techniques alongside new technologies such as the NordBord Hamstring Dynamometer. ${ }^{1}$ MMT is a subjective measure that evaluates strength of specific muscle groups against resistance provided by the clinician. Strength is graded on a scale from zero (unable to produced measurable muscle activity) to five (strong resistance) based on the clinician's subjective perception of the degree of provided resistance. Unfortunately, this technique lacks the precision that is required in clinical cases such as return to sport assessment, where between-limb differences of $10 \%$ may be clinically relevant, yet undetectable through MMT. $^{2}$

Isokinetic dynamometers are considered the gold standard for strength testing as they have been tested for validity and reliability ${ }^{3-5}$ and can test multiple muscle actions (isokinetic, isometric, isotonic). However, they are expensive and space consuming, which may limit their use. ${ }^{6}$ Given the imprecision of MMT and the expense of an isokinetic dynamometer, testing with HHD is becoming more common due to its ease in testing, reproducibility, and reduced cost. ${ }^{6,7}$

Previous authors have reported good to excellent interand intra-rater reliability for clinician-stabilized HHD and a high degree of correlation with isokinetic dynamometry, ${ }^{8}$ yet some concerns remain with this technique. ${ }^{1,7,9}$ Clinician-stabilized HHD has good agreement with isokinetic dynamometry, ${ }^{3,9-12}$ however variations in correlations can be expected given that differing contraction modes are often tested (i.e. isometric HHD against isokinetic concentric/ eccentric actions). ${ }^{8}$ The inability to maintain a stable isometric contraction during testing on the part of the clinicians or patient can lead to unreliable and imprecise results. Kelln et $\mathrm{al}^{13}$ suggest that with increasing levels of movement difficulty or strength output, HHD measurements become less reliable. As such, strength of the tester may be a limiting factor for MMT and HHD as well as lack of stabilization of the tester, subject, and device, especially when measuring stronger muscle groups. ${ }^{14,15}$ If testers of different sexes perform the same measurements, the inter-tester reliability can be questioned when using HHD, especially when testing larger muscles. ${ }^{15,16}$ This may contribute to the wide range of standard error of measurements (SEM) that have been observed across the literature (SEM 3.8-13.5\%). ${ }^{17}$ Despite these concerns, many authors report moderate to high levels of concurrent validity with isokinetic dynamometers ${ }^{8}$ and acceptable inter- and intra-rater reliability when comparing HHD to isokinetic dynamometers.

Anchoring the HHD to an immovable object may address the limitations of clinician-stabilized HHD. ${ }^{3,5,6,18-21}$ Various iterations of stabilization have been used, from engineered metallic frames, ${ }^{22,23}$ strapping the dynamometer to an immovable object, $, 9,24,25$ or bracing using PVC pipes. ${ }^{26}$ By externally 'bracing' the dynamometer, instead of holding it while the subject exerts their maximal force against it, the results are no longer dependent on either the examiner or the subject's strength. ${ }^{1}$ Not surprisingly, devices that provide stability to the dynamometer are associated with good to excellent intra-tester and inter-tester reliability; however, the majority of studies have focused on the hip with fewer regarding the knee flexors. ${ }^{9,12,19,24}$ Agreement between fixed and instrumented dynamometry is variable depending on contraction mode, device tested and muscles evaluated. ${ }^{12,24,25}$ Kim et $\mathrm{al}^{19}$ found that correlation in knee flexor peak torque was greater when fixed versus clinician stabilized HHD alone when compared with isokinetic dynamometry. Recently Martins et $\mathrm{al}^{25}$ found fixed HHD to show moderate to high correlation with isokinetic dynamometry, yet absolute values are likely not interchangeable between the devices. Consequently, further validation is required for externally fixed-HHD, considering both the validity and agreement with isokinetic dynamometry.

Strength assessment of the hamstrings is complicated due to the anatomical complexity of the muscle group. Differences in torque have been noted with the highest values occurring in the seated as compared with supine and prone positions ${ }^{27,28}$ which may be attributable to alterations in length and utilization of differing components of the hamstrings. Generally, knee flexion torque is greater with increasing hip flexion (seated versus supine and prone) and with lower levels of knee flexion. The most common positioning across the literature had the participant seated with the hip at or near $90^{\circ}$ flexion, and the knee between $30^{\circ}$ and $90^{\circ}$ of flexion. $1,4,5,11,12,29-37$ Only a few studies have positioned participants in prone, ${ }^{3,38,39}$ or with larger angles of hip flexion to more closely replicate striding position during gait. ${ }^{40}$ Knee flexion torque may also be influenced by the position of the ankle in dorsi- or plantarflexion as the gastrocnemius is a bi-articular muscle at both the ankle and the knee. Knee flexion moments of the gastrocnemius decrease with knee flexion and increase with greater degrees of dorsiflexion. ${ }^{41}$ The majority of the literature investigates differing angles at a single joint, when it is apparent that concurrent alterations in hip, knee and ankle position may 
impact isometric knee flexion torque and potentially, the clinical implications of the test. There is a paucity of research examining the impact of concurrent hip and ankle joint angles on isometric strength testing. Consequently, in addition to considerations of stabilization, clinicians must be aware of the impact of foot and hip position on knee flexion torque.

While HHD appears to be a viable alternative to isokinetic dynamometry, questions remain regarding the validity and reliability of fixed HHD and the NordBord dynamometer and the impact of hip and foot position on isometric knee flexion strength. The purpose of this study was to 1 ) investigate the validity and test-retest reliability of isometric knee flexion strength measured by a fixed HHD apparatus compared to a $\mathrm{BD}, 2$ ) determine the impact of body position (seated versus supine) and foot position (plantar- vs dorsiflexed) on knee flexion peak torque and 3) establish the validity and test-retest reliability of the NordBord Hamstring Dynamometer. It was hypothesized that fixed-HHD would provide a level of agreement with BD that would not permit interchange of values between devices and have high inter-rater reliability. Knee flexor strength was hypothesized to be greater in the seated and dorsiflexed position relative to supine testing with the ankle in plantarflexion. Finally, the NordBord was anticipated to have a low to moderate correlation with isometric testing completed on the $\mathrm{BD}$, given the differences in contraction mode assessed, and have excellent test-retest reliability.

\section{METHODS}

\section{SUBJECTS}

Forty-four healthy participants (22 males, 22 females, age: $27.1 \pm 4.8$ years, height: $172.2 \pm 9.3 \mathrm{~cm}$, weight: $74.8 \pm$ $13.8 \mathrm{~kg}$, Table 1) with no history of neurological conditions, chronic lower extremity injury or lower extremity reconstructive surgeries participated in two experimental sessions separated by three to seven days. Participants were instructed to maintain their regular activities but to avoid intensive lower extremity training the day immediately prior to both testing sessions. This study was approved by the University of Manitoba Health Research Ethics Board and was completed in accordance to the recommendations of the Declaration of Helsinki. Participants were informed of all study procedures and provided written informed consent prior to participation.

\section{PROCEDURES}

At the beginning of each testing day, the participant completed a five-minute warm up on a cycle ergometer at a self-selected pace and resistance, followed by lower body stretching as required. Following the five-minute warm up, participants were tested on a HHD, the BD, and a NordBord in each session. The order of the HHD and BD were randomized in the first session, and this order was maintained on the second testing day. The NordBord was completed at the end of the session both days. The HHD (Chatillon DFX2, Ametek, PA, USA) was externally fixed to the wall by a glass suction cup via two S-biners (Nite-Ize, Boulder, CO, USA) each rated to 100 pounds of tension and the suction cup

\section{Table 1: Participant characteristics}

\begin{tabular}{lc}
\hline & Mean \pm SD \\
\hline Age $(\mathrm{yrs})$ & $27.18 \pm 4.8$ \\
Height $(\mathrm{cm})$ & $172.17 \pm 9.39$ \\
Weight $(\mathrm{kg})$ & $74.8 \pm 14$ \\
L Shank Length $(\mathrm{cm})$ & $40.48 \pm 2.11$ \\
R Shank Length $(\mathrm{cm})$ & $40.66 \pm 2.51$ \\
\hline
\end{tabular}

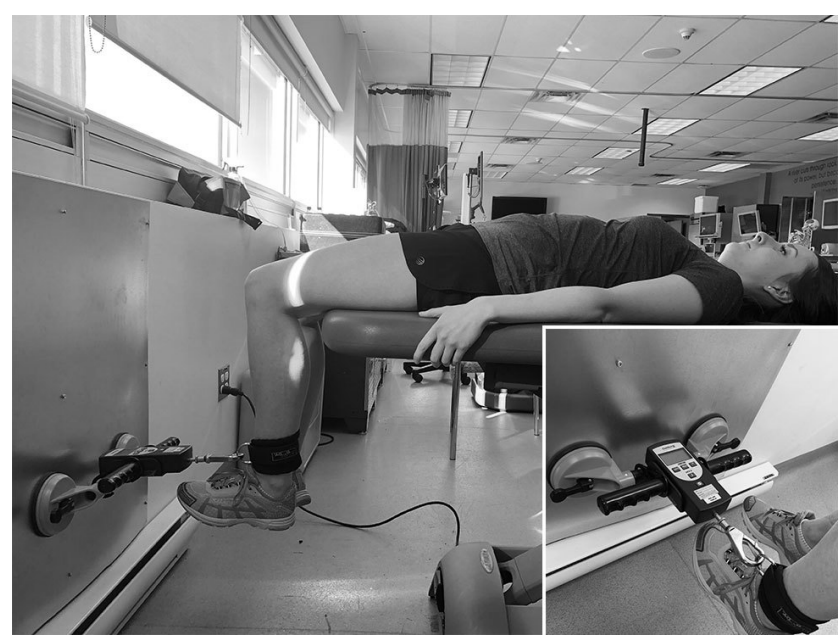

Figure 1: Equipment set up.

was secured to a metal sheet affixed to the wall. The HHD was outfitted with a hook-shaped clip insert that allowed an inelastic Velcro strap that looped around the participant's lower limb to connect to the HHD via a metal loop (Figure 1).

Testing was also performed on an isokinetic dynamometer (Biodex System3, Biodex Medical Systems, Shirley, NY) and eccentric knee flexion force and torque was measured during the Nordic Hamstring curl with the NordBord Hamstring dynamometer (NordBord; Vald Performance, Newstead, Australia), both operated according to the manufacturer's recommendations.

HHD data were collected by three investigators (two per participant) to assess inter-rater reliability, whereas the Biodex and NordBord data were collected by the same single investigator. Device order (BD, HHD, Nordbord) was standardized across days based on the day one randomization whereas rater order and ankle position (plantar flexion vs dorsiflexion) were randomized between sessions. The NordBord test was completed by the same rater at the end of each testing day, and the seated and supine positions were tested on day one and two respectively. Three attempts were provided on each device and position with a five-second hold for isometric actions, a 10-second break between maximal contractions, a 30-second break between different foot positions, and a five-minute break between devices. 


\section{SEATED ISOMETRIC STRENGTH PROTOCOL}

Testing with the HHD in the seated position consisted of the participant having both hips and knees in $90^{\circ}$ flexion with their popliteal fossae approximately two finger widths away from the edge of the therapy bed to negate any bracing effect. A Velcro strap with a metal loop for attachment to the HHD was secured to the participant's ankle two centimeters proximal to the lateral malleolus, measured from its point of greatest protrusion. The rater adjusted the height of the bed to ensure the line of force from the strap on the HHD was parallel to the floor and perpendicular to the participant's leg. The rater ensured the participant's tested knee remained at $90^{\circ}$ of flexion, that the participant's arms were at their sides with hands holding the edges of the bed, and that there was no excessive trunk or hip flexion throughout the isometric contractions through all trials.

Positioning in the BD was similar to that of the HHD with the participant seated with their back against a backrest positioned at $90^{\circ}$ above the horizontal, their hips and knees in $90^{\circ}$ of flexion, and their arms at their sides with their hands holding the handles of the chair. The axis of rotation of the dynamometer lever arm was positioned coaxial to the lateral femoral epicondyle. The shank was fixed to the lever arm two centimeters proximal to the lateral malleolus again, to keep the active lever arm length consistent between devices. Stabilization straps were secured diagonally across the participant's chest, and across their waist and thigh of the tested leg, to assure accurate, reproducible testing by controlling excessive movement. Once the participant was positioned, they were familiarized with the testing apparatus and performed two practice repetitions (fivesecond hold) prior to testing.

\section{SUPINE ISOMETRIC STRENGTH PROTOCOL}

The participant was positioned in neutral hip alignment $\left(0^{\circ}\right.$ hip flexion) and $90^{\circ}$ knee flexion, with the other limb positioned in a relaxed position. The rater aligned the subject and HHD in the same manner as outlined for seated testing. For testing with the $\mathrm{BD}$ in the supine position, the participant was laying against the backrest oriented at $5^{\circ}$ above the horizontal with their hips at approximately $0^{\circ}$ flexion and knees at $90^{\circ}$ flexion. The rater again aligned the Biodex System 3 and participant in the same fashion as outlined for seated testing.

\section{NORDBORD ECCENTRIC STRENGTH PROTOCOL}

Eccentric knee flexor strength was assessed on the NordBord Hamstring dynamometer. Participants were positioned kneeling with their ankles in the posterior hook anchors on the device. They were instructed to stay straight through the hips and trunk, keeping their shoulders as in line with their knees as possible through the entire movement. The participant then began to lean forward, extending at the knee, and lowered themselves toward the ground as low and slow as possible, while pushing up into the hooks as hard as they could with their ankles. When they could no longer maintain this task, the participant released their contraction and caught themselves with their hands on the landing mat.

\section{STATISTICAL ANALYSIS}

Peak force $(\mathrm{N})$, and torque $(\mathrm{Nm})$ were recorded from each device. Shank length $(\mathrm{cm})$ of each participant was measured in order to convert force measurements attained from the HHD testing into torque values, to facilitate absolute comparisons between the HHD and the BD results. Three attempts were completed in each position and test (BD, HHD, NordBord) and the average torque (BD, HHD) and force (NordBord) from the three attempts was used in subsequent analysis. Bland-Altman limits of agreement (LOA) analysis were calculated from the difference between test and retest values plotted against the average of the trials, with $95 \%$ LOA calculated as 1.96 multiplied by the standard deviation of the difference (Prism Graphpad, CA, USA). A factorial ANOVA was conducted to determine the impact of differing foot position (plantar flexed (PF) or dorsiflexed (DF), body position (seated or supine), body side (left and right) and test types (BD, HHD, NordBord) on resultant torque values. Intraclass correlation (ICC) estimates and their 95\% confidence intervals were calculated using SPSS (IBM, Armonk, NY, USA). Criterion validity of the HHD and Nordbord were established relative to the BD measures through comparison of Pearson correlation coefficients and ICC. Finally, test-retest reliability of the NordBord was established through consideration of ICCs for the left and right lower extremities (two-way mixed effects, absolute agreement, mean $\mathrm{K}$ raters). Statistical significance was considered at $\mathrm{p}<0.05$ where appropriate. ICC values were classified as poor (ICC <0.50), moderate (ICC $=0.5-0.75$ ), good (ICC = $0.75-0.90$ ) or excellent (ICC $>0.90) .{ }^{42}$ Pearson correlation coefficients were classified as high $(r>=0.70)$, moderate $(r=$ $0.50-0.70)$, low $(r=0.30-0.50)$ and weak $(r<0.30)$.

\section{RESULTS}

\section{HHD VALIDITY AND INTER-RATER RELIABILITY}

Bland-Altman LOA analysis of isometric knee flexion torque between HHD and BD found low bias with wide limits of agreement relative to obtained test scores (Bias $-0.33 \mathrm{Nm}$, standard deviation (SD) of bias $13.5 \mathrm{Nm}$; 95\% LOA 26.13 $\mathrm{Nm},-26.79 \mathrm{Nm})$. Given the potential for heteroscedasticity in the comparison of HHD against BD, alternative analysis was run on logarithmic transformed data, yielding comparable bias with narrowed limits of agreement (Bias -0.0007 , SD of Bias 0.1169, 95\% LOA: -0.2298, -0.2284). Inter-rater reliability of the fixed HHD was high as all but one ICC exceeded 0.9 , with minimal variation between the differing testing conditions (body position, foot position; Table 2).

\section{BODY AND FOOT POSITION ON TORQUE}

Main effects were found for body $\left.\left(\mathrm{F}_{(1,43)}=584.9, p<0.001\right)\right)$ and foot $\left(F_{(1,43)}=57.6, \mathrm{p}<0.001\right)$ position with greater isometric peak torque found in seated, dorsiflexed positions as opposed to supine, plantar flexed positions with data collapsed by side (left and right) and test type (HHD and BD; Figure 2). 
Table 2: Inter-rater reliability of the Handheld Dynamometer across body and foot positions

\begin{tabular}{lccccc}
\hline Position & Rater 1 $(\mathrm{Nm})$ & Rater 2 $(\mathrm{Nm})$ & ICC $(95 \% \mathrm{Cl})$ & SEM $(\mathrm{Nm})$ & MDC $_{95}(\mathrm{Nm})$ \\
\hline Seated, Dorsiflexed, Left & $70.47 \pm 26.53$ & $68.39 \pm 28.42$ & $0.94(0.89,0.97)$ & 6.73 & 18.65 \\
Seated, Plantarflexed, Left & $62.26 \pm 23.23$ & $60.84 \pm 24.49$ & $0.93(0.87,0.96)$ & 6.31 & 17.50 \\
Seated, Dorsiflexed, Right & $69.50 \pm 26.11$ & $68.32 \pm 26.54$ & $0.97(0.95,0.99)$ & 4.56 & 12.64 \\
Seated, Plantarflexed, Right & $62.66 \pm 24.87$ & $57.67 \pm 22.07$ & $0.93(0.87,0.96)$ & 6.21 & 17.21 \\
Supine Dorsiflexed, Left & $41.72 \pm 14.21$ & $40.82 \pm 13.90$ & $0.92(0.85,0.96)$ & 3.98 & 11.02 \\
Supine Plantarflexed, Left & $31.97 \pm 10.54$ & $30.95 \pm 11.41$ & $0.92(0.85,0.95)$ & 3.1 & 8.60 \\
Supine, Dorsiflexed, Right & $40.33 \pm 13.65$ & $39.79 \pm 15.50$ & $0.94(0.89,0.97)$ & 3.57 & 9.89 \\
Supine, Plantarflexed, Right & $32.49 \pm 11.88$ & $30.14 \pm 11.25$ & $0.90(0.81,0.94)$ & 3.66 & 10.14 \\
\hline
\end{tabular}

$I C C=$ intraclass correlation coefficient, $C I=$ confidence interval, $S E M=$ Standard Error of the Measurement, $M D C_{95}=$ Minimum Detectable Change, $N m=$ Newton-Meter

Table 3: Correlations between Biodex Dynamometer measured isometric knee flexion torque and maximal eccentric knee flexor torque during the Nordic Hamstring Curl exercise

\begin{tabular}{lccc}
\hline Body and Foot Position & Biodex Isometric Torque (Nm) & Nordic Eccentric Torque (Nm) & Pearson Correlation (Sig) \\
\hline Seated, Dorsiflexed, Left & $71.4 \pm 25.80$ & $110.35 \pm 47.03$ & $0.665(p=0.001392)$ \\
Seated, Plantarflexed, Left & $61.92 \pm 23.15$ & $110.35 \pm 47.03$ & $0.608(p=0.004482)$ \\
Seated, Dorsiflexed, Right & $72.01 \pm 25.10$ & $107.20 \pm 43.41$ & $0.791(p=0.000033)$ \\
Seated, Plantarflexed, Right & $64.24 \pm 23.39$ & $107.20 \pm 43.41$ & $0.714(p=0.000407)$ \\
Supine Dorsiflexed, Left & $43.86 \pm 17.31$ & $110.35 \pm 47.03$ & $0.861(p=0.000001)$ \\
Supine Plantarflexed, Left & $32.37 \pm 13.85$ & $110.35 \pm 47.03$ & $0.743(p=0.000172)$ \\
Supine, Dorsiflexed, Right & $45.02 \pm 16.36$ & $107.20 \pm 43.41$ & $0.791(p=0.000033)$ \\
Supine, Plantarflexed, Right & $33.93 \pm 14.40$ & $107.20 \pm 43.41$ & $0.702(p=0.001)$ \\
\hline
\end{tabular}

A

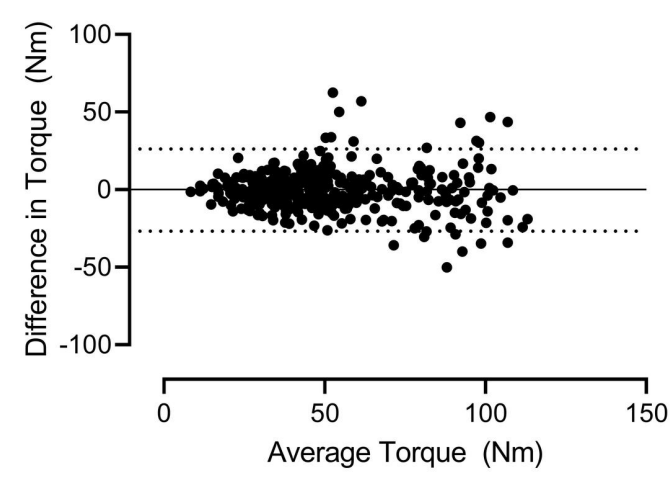

B

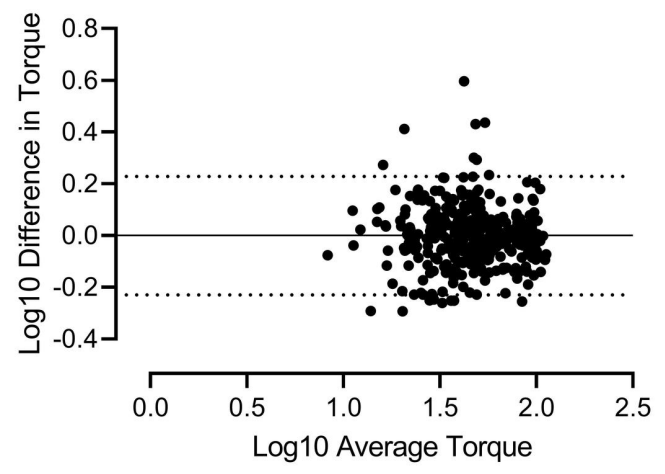

Figure 2: Difference in torque and $\log 10$ difference in torque by foot position

\section{NORDBORD VALIDITY AND TEST-RETEST RELIABILITY}

Moderate to high correlations were found between eccentric Nordbord hamstring torque and $\mathrm{BD}$ isometric torque, ranging from $r=0.61-0.86$, varying slightly with body and foot position for the BD (Table 3). Peak eccentric hamstring force during the NordBord Hamstring Curl displayed high testretest reliability (left leg: 0.993 (95\%CI $0.983-0.997)$; right Leg: 0.992 (95\%CI 0.979-0.997). $\mathrm{MDC}_{95}$ values for the left and right limb were $26.88 \mathrm{~N}$ and $28.76 \mathrm{~N}$ respectively (Table 4). 
Table 4: Test-retest reliability and $\mathrm{MDC}_{95}$ of the NordBord hamstring dynamometer force measurements

\begin{tabular}{lccccc}
\hline & Test 1 (N) & Test 2 (N) & ICC & SEM (N) & MDC $(\mathrm{N})$ \\
\hline Left & $276.98 \pm 119.68$ & $274.49 \pm 115.42$ & $0.993(0.98,0.997)$ & 19.31 & 26.88 \\
Right & $269.32 \pm 112.10$ & $271.93 \pm 116.63$ & $0.992(0.97,0.997)$ & 13.66 & 28.76 \\
\hline
\end{tabular}

ICC=intraclass correlation coefficient, $\mathrm{CI}=$ confidence interval, $\mathrm{SEM}=$ Standard Error of the Measurement, $\mathrm{MDC}_{95}=$ Minimum Detectable Change, Nm=Newton-Meter

\section{DISCUSSION}

The purpose of this study was to: 1) investigate the validity and reliability of isometric knee flexion strength measured with an externally fixed HHD compared to a BD, 2) determine the impact of hip and ankle position on isometric knee flexion strength and 3) assess the validity and test-retest reliability of the NordBord Hamstring Dynamometer.

\section{VALIDITY AND RELIABILITY OF FIXED-HHD}

With respect to the validity of fixed-HHD, a moderate to high degree of correlation with the BD was found, consistent with previous studies across various muscle groups. 3,5,10-12,19,25,43 The magnitude of correlation did not differ substantially between the seated and supine position or with plantar or dorsiflexion. Despite the degree of correlation between the two devices, the limits of agreement spanned more than $50 \mathrm{Nm}$ for the knee flexors. This is consistent with previous data from Lesnak et al ${ }^{10}$ who compared isometric knee extension peak torque between fixedHHD, finding limits of agreement of $19.4 \pm 53.2 \mathrm{Nm}$, and larger when evaluating rate of torque development. Martins et $\mathrm{al}^{25}$ demonstrated comparable correlations between the two machines, with similarly wide limits of agreement for the knee flexors. Katoh et $\mathrm{al}^{44}$ found higher forces with isokinetic dynamometers (tested isometrically) than with a belt stabilized HHD. As the design lacked a clinician-stabilized condition, it cannot be concluded that stabilization of the dynamometer improved agreement between BD and HHD. Data from Kim et $\mathrm{al}^{19}$ found correlation between the two devices were improved with fixation. Others have suggested that belt fixation is associated with greater force generation than clinician-stabilized conditions, and that HHD may underestimate strength relative to BD. ${ }^{19-21,24,25,44,45}$ Conversely, Lesnak et al ${ }^{10}$ found HHD to overestimate peak torque production yet underestimate the rate of torque development. Nevertheless, these results indicate that while instrumented assessment on isokinetic dynamometers and fixed HHD are correlated, values should not be interchanged between devices.

Inter-rater reliability of the fixed HHD was generally high and consistent with previous literature using fixed HHD for assessment of knee extensors ${ }^{12,19}$ and flexors. ${ }^{12,18,19,43,46}$ Romero-Franco et $\mathrm{al}^{43}$ tested a comparable seated knee flexion setup, anchoring the dynamometer to solid wall bars finding an ICC of 0.979 when retesting over a one week period. Differing from the present setup, both Wollin et $\mathrm{al}^{45}$ and Thorborg et $\mathrm{al}^{18}$ used a strap to anchor the dynamometer to the ground, with the patient near $0^{\circ}-30^{\circ}$ knee flexion in the prone position. While differences in knee flexion strength across the studies may represent differing contributions of components of the hamstring and gastrocnemius, inter-rater reliability was acceptable but lower than the present study (ICC 0.8 (95\%CI 0.65-0.93) and ICC 0.87 (95\%CI $0.75-0.93)$ ). Kim et $\mathrm{al}^{19}$ found fixation of the dynamometer to marginally improve inter-rater reliability against clinician-stabilized for the knee extensors (ICC 0.952 to 0.984 and 0.940 to 0.963 respectively); However, van der Made et $\mathrm{al}^{46}$ found fixation did not improve intertester reliability for isometric knee flexion in a cohort of rugby players of increased lower extremity strength, although all ICC values were 0.8 or higher. Nevertheless, this methodology displays excellent inter-rater reliability onpar with prior methodologies for fixed-HHD and indicates that HHD is acceptable for clinical use.

\section{EFFECT OF HIP AND ANKLE POSITION ON KNEE FLEXOR ISOMETRIC STRENGTH}

Given the biarticular structure of semitendinosus, long head biceps femoris, semimembranosus and gastrocnemius, hip, knee and ankle position must be considered when determining isometric knee flexion strength. Across the literature, assessment of knee flexion strength has been completed in the seated, prone and supine positions, although few, if any, direct comparisons of all three positions exist. Additional differences in the assessed contraction modes (i.e. isokinetic, isometric) further confound the comparison of knee flexion strength across studies by body position. In the present comparison of torque by position, collapsed for device (HHD and BD) knee flexion torque was greatest in the seated position with the foot dorsiflexed, and lowest in the supine position with the foot plantarflexed. Prior data evaluating concentric isokinetic strength generally agrees, finding increased torque with increased hip flexion in the seated as compared to the semi-reclined, supine and prone positions that is attributed to optimal positioning on the hamstring length-tension relationship with hip flexion beyond $90^{\circ} .27,47-50$ Consistent with these findings, Miller et $\mathrm{al}^{51}$ found an approximate $12 \%$ reduction in isokinetic knee flexion torque with the ankle in plantarflexion against dorsiflexion. Marchetti et $\mathrm{al}^{52}$ demonstrated a $22 \%$ difference in isometric knee flexion favoring the dorsiflexed versus plantar flexed position at $90^{\circ}$ knee flexion, although the magnitude of difference was reduced at $0^{\circ}$ knee flexion. Due to the biarticular nature of the gastrocnemius, plantar flexion of the ankle produces active insufficiency, and thus, reduced knee flexion torque. The values in the present study are lower than those previously observed. ${ }^{18,45}$ This may 
be attributed to differences between the sampled groups, prone versus supine positioning, and that testing at $90^{\circ}$ of knee flexion may result in reduced active contribution from the gastrocnemius, and reliance of differing components of the hamstring complex compared to those testing within lesser degrees of knee flexion. ${ }^{47,52-54}$ It is apparent that knee flexion torque varies with position of the hip, knee and ankle, and future studies should report and control these parameters.

\section{VALIDITY AND RELIABILITY OF THE NORDBORD HAMSTRING DYNAMOMETER}

Few studies have evaluated the NordBord Hamstring dynamometer against other methodologies of strength assessment like the isokinetic dynamometer or isometric HHD. These data indicate a strong correlation between isometric knee flexion and eccentric knee flexion torque during the Nordic Hamstring curl. The relationship between torque during the Nordic hamstring curl and isokinetic dynamometry is equivocal. Van Dyk et $\mathrm{al}^{55}$ found a poor degree of correlation between seated concentric and eccentric isokinetic knee flexion at $60 \%$ s and $300 \%$ s and eccentric Nordic hamstring curl torque. The authors attributed this to the characteristics of the tasks, whereby the hip is in a relatively neutral position during the Nordic hamstring curl opposed to seated knee flexion, and the bilateral nature of the Nordic hamstring curl as compared to unilateral isokinetic measures. Conversely, Lodge et al 56 assessed a comparable Nordic dynamometer (Hamstring Solo Elite) and found an inter-device correlation of 0.823 and 0.840 between the left and right limbs with isokinetic eccentric knee flexion torque at $30^{\circ} \mathrm{s}$. Our data may partially support this assertion, as the range and degree of correlations were slightly higher in the supine, hip neutral position as compared to the seated position. Inter-rater reliability of the NordBord exceeded the previously published values and is comparable to those observed by Lodge et $\mathrm{al}^{56}$ for the Hamstring Solo dynamometer. Consequently, the NordBord shows high test-retest reliability and a moderate correlation with isometric knee flexion assessed with the BD. Further work is required to clarify the relationship between differing test methodologies by body position and contraction mode.

\section{LIMITATIONS}

Although foot position was controlled for during the BD and HHD trials, it was not rigidly monitored during completion of the Nordic Hamstring Curl on the NordBord. Participants were given standardized instructions for positioning on the device that started with the foot in a neutral position; however, foot position was not specifically controlled during completion of the repetition. While foot position has been shown to be inconsequential for EMG amplitude in biceps femoris and the medial gastrocnemius, ${ }^{57}$ data on force production is lacking. A further limitation is that as we counterbalanced body position across testing days, our design did not allow for the determination of test-retest reliability for the externally fixed HHD.

\section{CONCLUSION}

The results of the present study serve to establish the validity of externally fixed HHD for the assessment of knee flexion strength against the BD. Wide limits of agreement despite low bias suggest that these values should not be interchanged between devices. As expected, inter-rater reliability of externally fixed HHD was also high. The position of the hip, knee and ankle must be considered as this may influence torque developed by the knee flexors. Future research is required to conclusively determine whether selective activation or utilization of the knee flexors may contribute to the differential in torque production, beyond changes in muscle length alone. The NordBord displayed moderate correlation with the $\mathrm{BD}$ despite testing differing contraction modes, and excellent test-retest reliability. U1timately, clinicians have various options available to them for the measurement of knee flexion strength, but must determine whether variation in testing device, contraction mode, and body position are relevant to the clinical issue at hand. Nevertheless, fixed HHD is valid and reliable for the assessment of knee flexor strength and is therefore a useful tool for clinicians who do not have access to other assessment methodologies such as isokinetic dynamometry.

\section{ACKNOWLEDGMENTS}

This work was generously supported by the Pan Am Clinic Foundation.

\section{CONFLICTS OF INTEREST}

The authors have no conflicts to declare.

Submitted: April 27, 2020 CDT, Accepted: November 03, 2020 CDT 


\section{REFERENCES}

1. Koblbauer IFH, Lambrecht Y, Van Der Hulst ML, et al. Reliability of maximal isometric knee strength testing with modified hand-held dynamometry in patients awaiting total knee arthroplasty: Useful in research and individual patient settings? A reliability study. BMC Musculoskelet Disord. 2011;12. doi:10.118 6/1471-2474-12-249

2. Bohannon RW. Manual muscle testing: Does it meet the standards of an adequate screening test? Clin Rehabil. 2005;19(6):662-667. doi:10.1191/026921 $5505 \mathrm{cr} 873 \mathrm{oa}$

3. Trudelle-Jackson E, Jackson AW, Frankowski CM, Long KM, Meske NB. Interdevice reliability and validity assessment of the Nicholas Hand-Held Dynamometer. J Orthop Sports Phys Ther. 1994;20(6):302-306. doi:10.2519/jospt.1994.20.6.302

4. Mau-Moeller A, Gube M, Felser S, et al. Intrarater reliability of muscle strength and hamstring to quadriceps strength imbalance ratios during concentric, isometric, and eccentric maximal voluntary contractions using the isoforce dynamometer. Clin J Sport Med. 2019;29(1):69-77. do i:10.1097/JSM.0000000000000493

5. Katoh M, Yamasaki H. Test-retest reliability of isometric leg muscle strength measurements made using a hand-held dynamometer restrained by a belt: Comparisons during and between Sessions. J Phys Ther Sci. 2009;21(3):239-243. doi:10.1589/ipts.21.239

6. Kollock RO, Onate JA, Van Lunen B. The reliability of portable fixed dynamometry during hip and knee strength assessments. J Athl Train.

2010;45(4):349-356. doi:10.4085/1062-6050-45.4.349

7. Neil SE, Myring A, Peeters MJ, et al. Reliability and validity of the Performance Recorder 1 for measuring isometric knee flexor and extensor strength.

Physiother Theory Pract. 2013;29(8):639-647. doi:10.3 109/09593985.2013.779337

8. Stark T, Walker B, Phillips JK, Fejer R, Beck R. Hand-held dynamometry correlation with the gold standard isokinetic dynamometry: A systematic review. PM R. 2011;3(5):472-479. doi:10.1016/i.pmrj.2 $\underline{010.10 .025}$

9. Whiteley R, Jacobsen P, Prior S, Skazalski C, Otten $\mathrm{R}$, Johnson A. Correlation of isokinetic and novel hand-held dynamometry measures of knee flexion and extension strength testing. J Sci Med Sport. 2012;15(5):444-450. doi:10.1016/j.jsams.2012.01.003
10. Lesnak J, Anderson D, Farmer B, Katsavelis D, Grindstaff TL. Validity of hand-held dynamometry in measuring quadriceps strength and rate of torque development. Int J Sports Phys Ther. 2019;14(2):180-187. doi:10.26603/ijspt20190180

11. Muff G, Dufour S, Meyer A, et al. Comparative assessment of knee extensor and flexor muscle strength measured using a hand-held vs. Isokinetic dynamometer. J Phys Ther Sci. 2016;28(9):2445-2451. doi:10.1589/jpts.28.2445

12. Mentiplay BF, Perraton LG, Bower KJ, et al. Assessment of lower limb muscle strength and power using hand-held and fixed dynamometry: A reliability and validity study. PLoS ONE. 2015;10(10). doi:10.137 1/journal.pone.0140822

13. Kelln BM, McKeon PO, Gontkof LM, Hertel J. Hand-held dynamometry: Reliability of lower extremity muscle testing in healthy, physically active, young adults. J Sport Rehabil. 2008;17(2):160-170. do $\mathrm{i}: 10.1123 /$ jsr.17.2.160

14. Wikholm JB, Bohannon RW. Hand-held dynamometer measurements: Tester strength makes a difference. J Orthop Sports Phys Ther. 1991;13(4):191-198. doi:10.2519/jospt.1991.13.4.191

15. Wadsworth CT, Nielsen DH, Corcoran DS, Phillips $\mathrm{CE}$, Sannes TL. Interrater reliability of hand-held dynamometry: Effects of rater gender, body weight, and grip strength. J Orthop Sports Phys Ther. 1992;16(2):74-81. doi:10.2519/jospt.1992.16.2.74

16. Thorborg K, Bandholm T, Schick M, Jensen J, Hölmich P. Hip strength assessment using handheld dynamometry is subject to intertester bias when testers are of different sex and strength. Scand J Med Sci Sport. 2013;23(4):487-493. doi:10.1111/j.1600-083 8.2011.01405.x

17. Chamorro C, Armijo-Olivo S, De La Fuente C, Fuentes J, Javier Chirosa L. Absolute reliability and concurrent validity of hand held dynamometry and isokinetic dynamometry in the hip, knee and ankle joint: Systematic review and meta-analysis. Open Med. 2017;12(1):359-375. doi:10.1515/med-2017-005 $\underline{2}$

18. Thorborg K, Bandholm T, Hölmich P. Hip- and knee-strength assessments using a hand-held dynamometer with external belt-fixation are intertester reliable. Knee Surgery, Sport Traumatol Arthrosc. 2013;21(3):550-555. doi:10.1007/s00167-012-2115-2 
19. Kim WK, Kim DK, Seo KM, Kang SH. Reliability and validity of isometric knee extensor strength test with hand-held dynamometer depending on its fixation: A pilot study. Ann Rehabil Med.

2014;38(1):84-93. doi:10.5535/arm.2014.38.1.84

20. Bohannon RW, Kindig J, Sabo G, Duni AE, Cram P. Isometric knee extension force measured using a handheld dynamometer with and without beltstabilization. Physiother Theory Pract. 2012;28(7):562-568. doi:10.3109/09593985.2011.6403 $\underline{85}$

21. Bohannon RW, Bubela DJ, Wang YC, Magasi SR, Gershon RC. Adequacy of belt-stabilized testing of knee extension strength. J Strength Cond Res. 2011;25(7):1963-1967. doi:10.1519/ISC.0b013e3181e4 f5ce

22. Nadler SF, DePrince ML, Hauesien N, Malanga GA, Stitik TP, Price E. Portable dynamometer anchoring station for measuring strength of the hip extensors and abductors. Arch Phys Med Rehabil.

2000;81(8):1072-1076. doi:10.1053/apmr.2000.7165

23. Scott DA, Bond EQ, Sisto SA, Nadler SF. The intraand interrater reliability of hip muscle strength assessments using a handheld versus a portable dynamometer anchoring station. Arch Phys Med Rehabil. 2004;85(4):598-603. doi:10.1016/j.apmr.200 $\underline{3.07 .013}$

24. Toonstra J, Mattacola CG. Test-retest reliability and validity of isometric knee-flexion and -extension measurement using 3 methods of assessing muscle strength. J Sport Rehabil. 2013;22(1):1-5. doi:10.1123/ jsr.2013.tr7

25. Martins J, Da Silva JR, Da Silva MRB, BevilaquaGrossi D. Reliability and validity of the belt-stabilized handheld dynamometer in hip-and knee-strength tests. J Athl Train. 2017;52(9):809-819. doi:10.4085/10 62-6050-52.6.04

26. Jackson SM, Cheng MS, Smith AR, Kolber MJ. Intrarater reliability of hand held dynamometry in measuring lower extremity isometric strength using a portable stabilization device. Musculoskelet Sci Pract. 2017;27:137-141. doi:10.1016/j.math.2016.07.010

27. Worrell TW, Perrin DH, Denegar CR. The influence of hip position on quadriceps and hamstring peak torque and reciprocal muscle group ratio values. $J$ Orthop Sports Phys Ther. 1989;11(3):104-107. doi:10.2 519/jospt.1989.11.3.104

28. Worrell TW, Denegar CR, Armstrong SL, Perrin DH. Effect of body position on hamstring muscle group average torque. J Orthop Sports Phys Ther. 1990;11(10):449-452. doi:10.2519/jospt.1990.11.10.44 $\underline{9}$
29. McHugh MP, Nesse M. Effect of stretching on strength loss and pain after eccentric exercise. Med Sci Sports Exerc. 2008;40(3):566-573. doi:10.1249/MS S.0b013e31815d2f8c

30. Ardern CL, Pizzari T, Wollin MR, Webster KE. Hamstrings strength imbalance in professional football (Soccer) players in Australia. J Strength Cond Res. 2015;29(4):997-1002. doi:10.1519/ISC.000000000 $\underline{0000747}$

31. Koulouris G. Imaging review of groin pain in elite athletes: An anatomic approach to imaging findings. Am J Roentgenol. 2008;191(4):962-972. doi:10.2214/AI $\underline{\text { R.07.3410 }}$

32. Macaluso A, Nimmo MA, Foster JE, Cockburn M, McMillan NC, De Vito G. Contractile muscle volume and agonist-antagonist coactivation account for differences in torque between young and older women. Muscle and Nerve. 2002;25(6):858-863. doi:1 0.1002/mus.10113

33. Ancillao A, Rossi S, Cappa P. Analysis of knee strength measurements performed by a hand-held multicomponent dynamometer and optoelectronic system. IEEE Trans Instrum Meas. 2017;66(1):82-92. $\underline{\mathrm{d}}$ oi:10.1109/TIM.2016.2620799

34. Cortes N, Greska E, Kollock R, Ambegaonkar J, Onate JA. Changes in lower extremity biomechanics due to a short-term fatigue protocol. J Athl Train. 2013;48(3):306-313. doi:10.4085/1062-6050-48.2.03

35. de Vasconcelos RA, Bevilaqua-Grossi D, Shimano AC, et al. Reliability and Validity of a Modified Isometric Dynamometer in the Assessment of Muscular Performance in Individuals With Anterior Cruciate Ligament Reconstruction. Rev Bras Ortop (English Ed). 2009;44(3):214-224. doi:10.1016/s2255-4 971(15)30071-9

36. Krasnow D, Ambegaonkar JP, Stecyk S, Wilmerding MV, Wyon M, Koutedakis Y. Development of a Portable Anchored Dynamometer for Collection of Maximal Voluntary Isometric Contractions in Biomechanics Research on Dancers. Med Probl Perform Art. 2011;26(4):185-194.

37. Douma RKW, Soer R, Krijnen WP, Reneman M, van der Schans CP. Reference values for isometric muscle force among workers for the Netherlands: A comparison of reference values. BMC Sports Sci Med Rehabil. 2014;6(1). doi:10.1186/2052-1847-6-10

38. Akagi R, Tohdoh Y, Takahashi H. Strength and size ratios between reciprocal muscle groups in the thigh and lower leg of male collegiate soccer players. Clin Physiol Funct Imaging. 2014;34(2):121-125. doi:10.111 $\underline{1 / \mathrm{cpf} .12073}$ 
39. Akagi R, Tohdoh Y, Takahashi H. Muscle strength and size balances between reciprocal muscle groups in the thigh and lower leg for young men. Int J Sports Med. 2012;33(5):386-389. doi:10.1055/s-0031-129970 $\underline{0}$

40. Matsuo S, Suzuki S, Iwata M, et al. Acute effects of different stretching durations on passive torque, mobility, and isometric muscle force. J Strength Cond Res. 2013;27(12):3367-3376. doi:10.1519/ISC.0b013e3 18290c26f

41. Li L, Landin D, Grodesky J, Myers J. The function of gastrocnemius as a knee flexor at selected knee and ankle angles. J Electromyogr Kinesiol. 2002;12(5):385-390. doi:10.1016/S1050-6411(02)0004 $\underline{9-4}$

42. Koo TK, Li MY. A guideline of selecting and reporting intraclass correlation coefficients for reliability research. Journal of Chiropractic Medicine. 2016;15(2):155-163. doi:10.1016/j.jcm.2016.02.012

43. Romero-Franco N, Jiménez-Reyes P, MontañoMunuera JA. Validity and reliability of a low-cost digital dynamometer for measuring isometric strength of lower limb. Journal of Sports Sciences. 2017;35(22):2179-2184. doi:10.1080/02640414.2016.1 260152

44. Katoh M, Hiiragi Y, Uchida M. Validity of isometric muscle strength measurements of the lower limbs using a handheld dynamometer and belt: A comparison with an isokinetic dynamometer. J Phys Ther Sci. 2011;23(4):553-557. doi:10.1589/jpts.23.553

45. Wollin M, Purdam C, Drew MK. Reliability of externally fixed dynamometry hamstring strength testing in elite youth football players. J Sci Med Sport. 2016;19(1):93-96. doi:10.1016/j.jsams.2015.01.012

46. van der Made AD, Paget LDA, Altink JN, et al. Assessment of isometric knee flexor strength using hand-held dynamometry in high-level rugby players is intertester reliable. Clin J Sport Med. December 2019:1. doi:10.1097/jsm.0000000000000793

47. Kellis E, Galanis N, Kofotolis N, Hatzi A. Effects of hip flexion angle on surface electromyographic activity of the biceps femoris and semitendinosus during isokinetic knee flexion. Muscles Ligaments Tendons J. 2017;7(2):286-292. doi:10.11138/mltj/201 7.7.2.286

48. Black SJ, Woodhouse ML, Suttmiller S, Shall L. Influence of hip position on electromyographic and torque productions in the knee. J Sport Rehabil. 1993;2(1):26-34. doi:10.1123/jsr.2.1.26
49. Findley BW, Brown LE, Whitehurst M, Keating T, Murray DP, Gardner LM. The influence of body position on load range during isokinetic knee extension/flexion. J Sport Sci Med. 2006;5(3):400-406.

50. Bohannon RW, Gajdosik RL, LeVeau BF. Isokinetic knee flexion and extension torque in the upright sitting and semireclined sitting positions. Phys Ther. 1986;66(7):1083-1086. doi:10.1093/pti/66.7.1083

51. Miller JP, Catlaw K, Confessore R. Effect of ankle position on EMG activity and peak torque of the knee extensors and flexors during isokinetic testing. J Sport Rehabil. 1997;6(4):335-342. doi:10.1123/isr.6.4.335

52. Marchetti PH, Magalhaes RA, Gomes WA, da Silva JJ, Stecyk SD, Whiting WC. Different Knee and Ankle Positions Affect Force and Muscle Activation During Prone Leg Curl in Trained Subjects. J Strength Cond Res. 2019:1. doi:10.1519/jsc.0000000000003333

53. Onishi H, Yagi R, Oyama M, Akasaka K, Ihashi K, Handa Y. EMG-angle relationship of the hamstring muscles during maximum knee flexion. J Electromyogr Kinesiol. 2002;12(5):399-406. doi:10.1016/S1050-641 $\underline{1(02) 00033-0}$

54. Worrell TW, Karst G, Adamczyk D, et al. Influence of joint position on electromyographic and torque generation during maximal voluntary isometric contractions of the hamstrings and gluteus maximus muscles. J Orthop Sports Phys Ther. 2001;31(12):730-740. doi:10.2519/jospt.2001.31.12.73 $\underline{0}$

55. van Dyk N, Witvrouw E, Bahr R. Interseason variability in isokinetic strength and poor correlation with Nordic hamstring eccentric strength in football players. Scand J Med Sci Sport. 2018;28(8):1878-1887. doi:10.1111/sms.13201

56. Lodge C, Tobin D, O’Rourke B, Thorborg K. Reliability and Validity of a New Eccentric Hamstring Strength Measurement Device. Arch Rehabil Res Clin Transl. November 2019:100034. doi:10.1016/i.arrct.20 19.100034

57. Comfort P, Regan A, Herrington L, Thomas C, McMahon J, Jones P. Lack of effect of ankle position during the Nordic curl on muscle activity of the biceps femoris and medial gastrocnemius. J Sport Rehabil. 2017;26(3):202-207. doi:10.1123/jsr.2015-013 